\title{
Investigation of the Effect of Rosmarinic Acid on Cyclophosphamide-Induced Gonadal Toxicity
}

\author{
Fırat Şahin*, Fırat Aşır, Ebru Gökalp Özkorkmaz, Süreyya Özdemir Başaran, \\ Özge Kaplan, Işılay Sezen Ermiş, Engin Deveci
}

Department of Histology and Embryology, Faculty of Medicine, Dicle University, Diyarbakir, Turkey

Email: *sfirat9021@gmail.com

How to cite this paper: Şahin, F., Aşır, F., Özkorkmaz, E.G., Başaran, S.Ö., Kaplan, Ö., Ermiş, I.S. and Deveci, E. (2022) Investigation of the Effect of Rosmarinic Acid on Cyclophosphamide-Induced Gonadal Toxicity. Advances in Sexual Medicine, 12, 1-8. https://doi.org/10.4236/asm.2022.121001

Received: October 15, 2021

Accepted: December 5, 2021

Published: December 8, 2021

Copyright $\odot 2022$ by author(s) and Scientific Research Publishing Inc. This work is licensed under the Creative Commons Attribution International License (CC BY 4.0).

http://creativecommons.org/licenses/by/4.0/

(c) (i) Open Access

\begin{abstract}
The aim of this study was to investigate the effect of rosmarinic acid against gonadal toxicity caused by cyclophosphamide, an important anticancer drug. A total of 28 rats were divided into 4 groups, with 7 animals in each group. The groups were created as follows; Group 1 (control) $(n=7)$ : Subjects received only $1 \mathrm{ml}$ of $0.9 \%$ saline solution per day intraperitoneally for 14 days. Group 2 (Rosmarinic Acid) ( $\mathrm{n}=7$ ): The subjects were given $20 \mathrm{mg} / \mathrm{kg}$ Rosmarinic acid intraperitoneally for 14 days. Group 3 (Cyclophosphamide) ( $\mathrm{n}=$ 7): Only $1 \mathrm{ml}$ of $0.9 \%$ saline solution was administered intraperitoneally to the subjects for the first 7 days. Cyclophosphamide $20 \mathrm{mg} / \mathrm{kg}$ per day was administered intraperitoneally for the last 7 days (from the $8^{\text {th }}$ day). Group 4 (Rosmarinic Acid + Cyclophosphamide) $(\mathrm{n}=7)$ : The subjects were given 20 $\mathrm{mg} / \mathrm{kg}$ Rosmarinic acid daily intraperitoneally for 14 days. From the $8^{\text {th }}$ day of the experiment to the end of the experiment (last 7 days of the experiment), $20 \mathrm{mg} / \mathrm{kg}$ cyclophosphamide was given intraperitoneally daily. At the end of the experiment, body weights of all rats were measured first. Afterwards, the weights of testicular tissue samples were measured and the averages of the weights were taken. Routine tissue follows up was performed on the testicular tissues taken. Hematoxylin-eosin staining was applied to tissue sections of 5 $\mu \mathrm{m}$ thickness. As a result of the statistical analysis, it was determined that cyclophosmadine decreased body and testicular weight, but rosmarinic acid had a protective effect on the contrary. It was concluded that cyclophosmadine caused damage to the basement membrane structure, Sertoli, Leydig and germ cells, but these structures were preserved due to the protective effect of rosmarinic acid. Despite the toxic effect of $\mathrm{CP}$, rosmarinic acid is thought to have a significant curative effect on the spermatogenetic process and seminiferous tubule structure in the gonads.
\end{abstract}




\section{Keywords}

Testis, Cyclophosphamide, Rosmarinic Acid, Sertoli Cell, Hematoxylin Eosin

\section{Introduction}

Cyclophosphamide (CP) is one of the successful anticancer drugs ever designed. $\mathrm{CP}$ is still used as a chemotherapeutic agent for blood and bone marrow transplantation [1]. Although it is used in many clinical studies, it is known that $\mathrm{CP}$ has adverse effects such as reproductive toxicity [2]. In case of exposure to CP, significant histological changes such as weight loss in the gonads, degenerated spermatogenesis, oligozoospermia and azoospermia are observed [3]. The cause of gonadal toxicity from $\mathrm{CP}$ is unclear. However, studies know that it causes severe oxidative stress, apoptosis and inflammation [4]. The destructive damage that develops after the use of $\mathrm{CP}$ is difficult and takes years to recycle [5]. It is thought that the toxic effect of $\mathrm{CP}$ decreases after the application of ginseng, which is an antioxidant [6]. In a study, it was seen that ginger and vitamin $\mathrm{E}$ prevented gonadal toxicity against cyclophosphamide [7]. Rosmarinic acid (RA), which belongs to the Lamiaceae family, is a natural antioxidant found in most plants [8]. RA has effects such as immunomodulatory, antibacterial and antiviral activities [9]. Due to its antioxidant effect, rosmarinic acid is widely used in cosmetics and foods, as well as medical use. In addition, it has the ability to inhibit RA lipoxygenase and cyclooxygenase activity [10]. In studies, it is known that RA increases the level of serum testosterone [11].

In our study, we aimed to investigate the possible role of RA, which has an important antioxidant and immunomodulatory effect, against the toxic effect of $\mathrm{CP}$ on reproductive toxicity.

\section{Material and Method}

Ethical Approval and Experiment Procedure-Approved by Dicle University Animal Experiments Local Ethics Committee (ethical approval number: 2020/16). The experiment was carried out in Dicle University Experimental Animal Care Unit. In the experimental protocol, 28 animals, 15 - 16 weeks old, 200 - $250 \mathrm{~g}$ male Wistar Albino rats were used. Experimental animals were obtained from Dicle University Health Sciences Research and Application Center. This study, which is part of her doctoral study, was supported by Dicle University Scientific Research Projects (BAP). The subjects were housed in a 12-hour dark and 12-hour light cycle at room temperature $\left(22 \pm 2^{\circ} \mathrm{C}\right)$, in cages containing 7 animals, with free access to water and food. According to the experimental protocol, daily injections were made administered intraperitoneally (i.p) at the same time each day. Rosmarinic acid (CAS 20283-92-5, Santa Cruz Biotechnology,) was dissolved in $1 \%$ alcohol, filtered on filter paper and stored at $-20^{\circ} \mathrm{C}$ until use. 
All experimental groups were subjected to the following procedures for 14 days.

Group 1 (Control) ( $\mathbf{n}=7$ ): Subjects received only $1 \mathrm{ml}$ of $0.9 \%$ saline solution per day intraperitoneally for 14 days.

Group 2 (Rosmarinic Acid) ( $\mathrm{n}=7$ ): The subjects were given $20 \mathrm{mg} / \mathrm{kg}$ Rosmarinic acid intraperitoneally for 14 days.

Group 3 (Cyclophosphamide) $(\mathbf{n}=7)$ : Only $1 \mathrm{ml}$ of $0.9 \%$ saline solution was administered intraperitoneally to the subjects for the first 7 days. Cyclophosphamide $20 \mathrm{mg} / \mathrm{kg}$ per day was administered intraperitoneally for the last 7 days (from the $8^{\text {th }}$ day).

Group 4 (Rosmarinic Acid + Cyclophosphamide) ( $n=7)$ : The subjects were given $20 \mathrm{mg} / \mathrm{kg}$ Rosmarinic acid daily intraperitoneally for 14 days. From the $8^{\text {th }}$ day of the experiment to the end of the experiment (last 7 days of the experiment), $20 \mathrm{mg} / \mathrm{kg}$ cyclophosphamide was given intraperitoneally daily.

Experiment times and model and CP doses were designed based on the studies of Zina et al. [12] and Sabik et al. [13].

\section{Anesthesia and Surgical Procedures}

At the end of the experiment, rats were sacrificed under anesthesia of 75 $\mathrm{mg} / \mathrm{kg}$ intramuscular ketamine hydrochloride and $10 \mathrm{mg} / \mathrm{kg}$ xylazine. Testicular tissue was removed by performing lower fixed in abdominal dissection. Subsequently, testicular tissues were $\% 10$ formaldehyde.

\section{Histological examination}

$5-\mu \mathrm{m}$ thick sections were taken from parafin-embedded testicular tissues. After the deparaffinization process, the sections were passed through alcohol series and taken into distilled water. After the deparaffinized through alcohol series and taken into distilled water Hematoxylin Eosin dye (HE) was applied to sections. The stained sections were washed with distilled water, then passed through alcohol series and dehydrated. They were covered with entellan and examined under a light microscope (Zeiss, Imager A2, Germany).

\section{Statistical analysis}

The data obtained in the study was expressed as an arithmetic mean \pm standard deviation and the Mean Rank value. Statistical analysis was performed using SPSS 22.0 program. In Multiple comparison, Kruskal-Wallis test was used. $\mathrm{p}$ $<0.05$ was accepted as significant.

\section{Results}

\section{Statistical findings}

Cyclophosphamide group according to the statistical data obtained body and testicular weights of rats belonging to the group statistically compared to other groups. When the cyclophosphamide group was compared with the other groups, a significant difference was detected $(\mathrm{p}<0.05)$ (Table 1$)$. In addition, when we compared the cyclophosphamide group with the rosmarinic acid and rosmarinic acid + cyclophosphamide group, we found that there was a signifi- 
cant difference. Except for the cyclophosphamide group, it was determined that there was no difference between the other groups $(p>0.05)$.

\section{Histopathological findings}

Hematoxylin-eosin impressions of the groups are shown in Figure 1. Seminiferous tubule structure in the testes of the control group is normal in hematoxylin-eosin stained sections. Spermatogonia appear normal towards the lumen. Sertoli cells were observed to have broad bases and an upward triangular structure (Figure 1(a)). When we examined the rosmarinic acid group (Figure 1(b)), in the transversal section of the seminiferous tubules, spermatogonia close to the basal lamina were found to be chromatin-rich and oval in shape. It was determined that Sertoli cells had a triangular structure and that the maturing spermatogonium

Table 1. Shows experimental groups with their body weight \pm standard deviation (SD) and testicular weight \pm standard deviation SD.

\begin{tabular}{ccc}
\hline GRUOPS & Body Weight (gr) & Testicular Weight (gr) \\
\hline Group 1 (Control) $(\mathrm{n}=7)$ & $225.12 \pm 22.10$ & $1.14 \pm 0.24$ \\
Group 2 (Rosmarinic Acid) $(\mathrm{n}=7)$ & $200.33 \pm 21.35$ & $1.17 \pm 0.30$ \\
Group 3 (Cyclophosphamide) $(\mathrm{n}=7)$ & $140.17 \pm 12.28$ & $0.8 \pm 0.21$ \\
$\begin{array}{c}\text { Group 4 (Rosmarinic Acid }+ \\
\text { Cyclophosphamide) }(\mathrm{n}=7)\end{array}$ & $196.50 \pm 35.12$ & $1.15 \pm 0.15$ \\
\hline
\end{tabular}

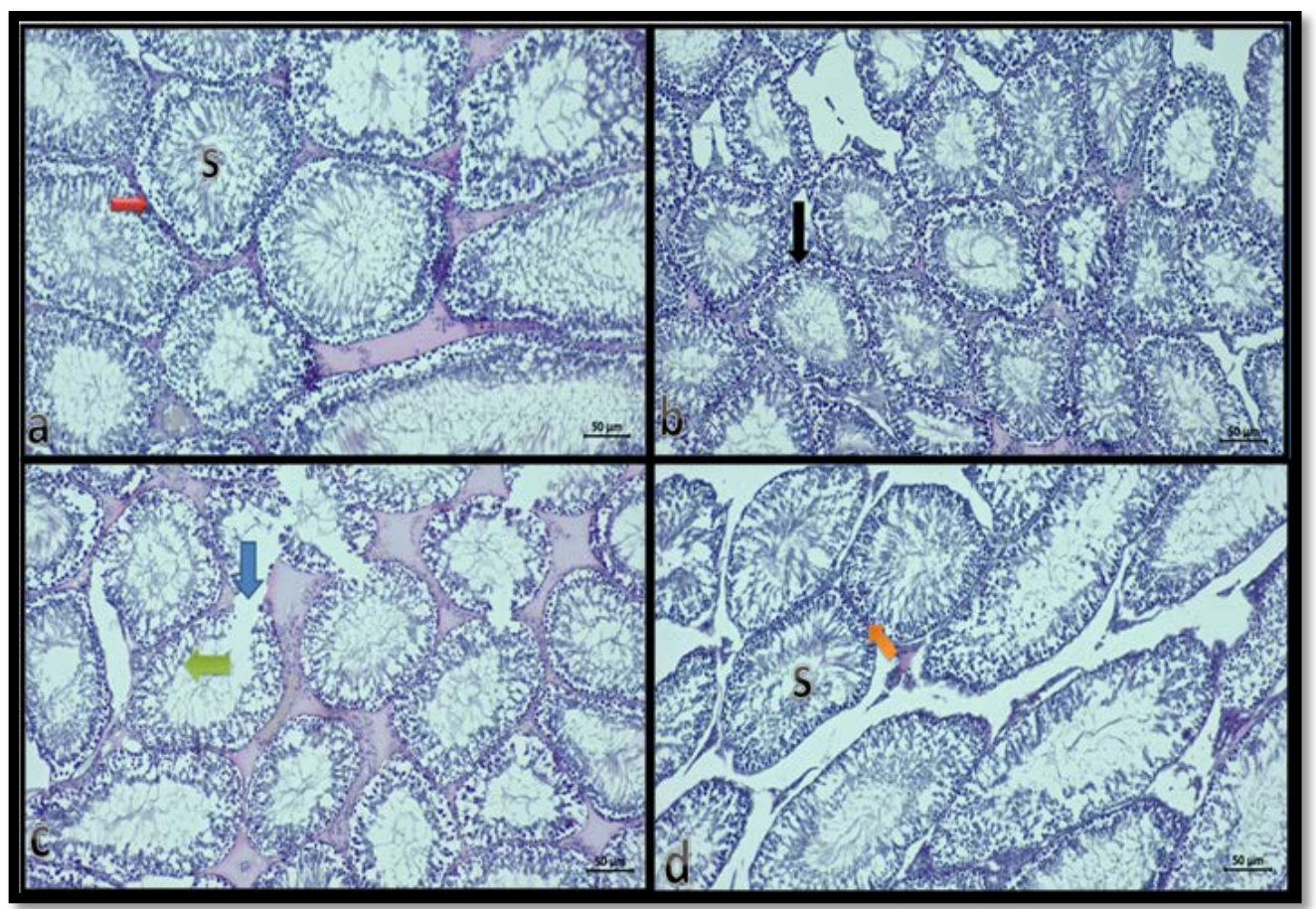

Figure 1. (a) Control group: Seminiferous tubule (s), basal membrane (red arrow) (b) Rosmarinic acid group: Normal appearance spermatogonia (black arrow). (c) Cyclophosphamide group: Disruption of basement membrane integrity (blue arrow), degenerated spermatogonia (green arrow) (d) Cyclophosphamide and rosmarinic acid group: Basement membrane (orange arrow), regularly arranged spermatogonia (s) (H \& E, $50 \mu \mathrm{m})$. 
was normal in development. When the hematoxylin-eosin stained sections belonging to the cyclophosphamide group are examined (Figure $1(\mathrm{c})$ ). It is observed that the structural integrity of the basement membrane of the seminiferous tubules has been disrupted and the basement membrane has completely disappeared in some areas. The spermatogonia in the seminiferous tubule are degenerated and pyknosis is seen in their nuclei. A marked cell inflammation and edema are observed within the intertubular spaces. When the sections belonging to the cyclophosphamide and rosmarinic acid groups are examined (Figure 1(d)); despite the toxic effect of cyclophosphamide, the integrity of the basement membrane appears to be preserved. It is seen that the spermatogonia in the seminiferous tubule are partially degenerated, but overall integrity is provided. Sertoli and Leydig cells were found to have a normal appearance. It is seen that inflammation decreased in the intertubular area. It was determined that rosmarinic acid was protective on testes against tissue damage of cyclophosphamide.

\section{Discussion}

Cyclophosphamide (CP), an effective anticancer drug, was approved by the FDA in 1959 [14]. However, as a result of studies, it has been determined that CP has toxic effects on cardiac, testicular, kidney and liver [15]. It has been determined that there are deteriorations in the sperm structure in patients who use CP for more than 4 months [16]. There are data that cyclophosphamide also causes apoptosis [17]. In a study conducted on male rats in 2002, it was found that CP had an effect on decreasing testicular weight [18]. In our study, it was determined that cyclophosphamide was effective on testicular weight and there was a statistically significant difference when compared with other groups (Table 1). When Sung et al. compared testes and body weight in the CP group with the control group in their study in 2016, they found that there was a decrease in both testes and body weight in the cyclophosphamide group compared to the control group [19]. Our study shows parallelism with this study. In our study, we found that Rosmarinic acid has a protective effect on testicles and body weight, despite the toxic effect of CP (Figure 1). In a study conducted in 2016, it was determined that tissue integrity was impaired and germ cells were damaged in the testes of rats administered cyclophosphamide [20]. When the hematoxylin-eosin stained sections of the experimental study we conducted were examined, it was determined that the tissue integrity was impaired, and Sertoli cells and germ cells were damaged in the testes of rats administered cyclophosphamide (Figure $1(c)$ ). As a result of many experimental studies, it is known that $\mathrm{CP}$ has a toxic effect on the reproductive organs [21]. The findings we obtained with the toxic damage caused by CP in the testicles are similar to the findings obtained in other similar studies [22]. In experimental studies induced by cyclophosphamide, tissue integrity damage and apoptosis are observed [23]. There are also many reports that RA has an effect on inflammation. Studies have shown that RA inhi- 
bits complement activation both in vivo and in vitro [24]. However, there are no studies in the literature on whether rosmarinic acid is protective against the efficacy of CP. In this respect, it is important to investigate whether RA has prophylactic and anti-inflammatory effects in our study. In the study of Khaki et al. in 2012, it was observed that RA protects testicular tissue integrity and prevents apoptosis in rats exposed to electromagnetic field [11]. In our study, we obtained results showing that RA protects tissue integrity against the toxic effect of cyclophosphamide (Figure 1(d)). When we look at the findings of the cyclophosphamide group, disruptions in the basement membrane structure, pyknosis in Sertoli and germ cells were observed. These findings are similar to the work of Ghosh et al. [25]. As a result of our study, we observed that RA has a protective effect against toxic damage.

\section{Conclusion}

It was observed that cyclophosphamide inhibited spermiogenesis in gonads and Sertoli cell adhesion was affected. We think that RA has an antioxidant effect against CP toxicity. Despite the toxic effect of $\mathrm{CP}$, rosmarinic acid is thought to have a significant curative effect on the spermatogenetic process and seminiferous tubule structure in the gonads.

\section{Acknowledgements}

This study is a part of Firat ŞAHIN's doctoral thesis and was supported Research Projects (DUBAP) with the by Dicle University Scientific project number TIP.21.003.

\section{Conflicts of Interest}

The authors declare no conflicts of interest regarding the publication of this paper.

\section{References}

[1] Emadi, A., Jones, R.J. and Brodsky, R.A. (2009) Cyclophosphamide and Cancer: Golden Anniversary. Nature Reviews Clinical Oncology, 6, 638-647. https://doi.org/10.1038/nrclinonc.2009.146

[2] Selvakumar, E., Prahalathan, C., Sudharsan, P.T. and Varalakshmi, P. (2006) Chemoprotective Effect of Lipoic Acid against Cyclophosphamide-Induced Changes in the Rat Sperm. Toxicology, 217, 71-78. https://doi.org/10.1016/j.tox.2005.08.020

[3] Anan, H.H., Zidan, R.A., Abd EL-Baset, S.A. and Ali, M.M. (2018) Ameliorative Effect of Zinc Oxide Nanoparticles on Cyclophosphamide Induced Testicular Injury in Adult Rat. Tissue and Cell, 54, 80-93. https://doi.org/10.1016/j.tice.2018.08.006

[4] Maremanda, K.P., Khan, S. and Jena, G. (2014) Zinc Protects Cyclophosphamide-Induced Testicular Damage in Rat: Involvement of Metallothionein, Tesmin and Nrf2. Biochemical and Biophysical Research Communications, 445, 591-596. https://doi.org/10.1016/j.bbrc.2014.02.055

[5] Elangovan, N., Chiou, T.-J., Tzeng, W.-F. and Chu, S.-T. (2006) Cyclophosphamide 
treatment Causes Impairment of Sperm and Its Fertilizing Ability in Mice. Toxicology, 222, 60-70. https://doi.org/10.1016/j.tox.2006.01.027

[6] Kim, K.T., Yoo, K.M., Lee, J.W., Eom, S.H., Hwang, I.K. and Lee, C.Y. (2007) Protective Effect of Steamed American Ginseng (Panax quinquefolius L) on V79-4 Cells Induced by Oxidative Stress. Journal of Ethnopharmacology, 111, 443-450. https://doi.org/10.1016/j.jep.2007.01.004

[7] Li, D.J., Xu, Z.S., Zhang, Z.H. and Huang, Q.Y. (2006) Antagonistic Effects of Vitamin E on the Testicular Injury by Cyclophosphamide in Mice. National Journal of Andrology, 13, 853-857.

[8] Huang, Y.S. and Zhang, J.T. (1992) Antioxidative Effect of Three Watersoluble Components Isolated from Salvia miltiorrhiza in Vitro. Acta Pharmaceutica Sinica, 27, 96-100. [In Chinese]

[9] Oteiza, P.I., Erlejman, A.G., Verstraeten, S.V., Keen, C.L. and Fraga, C.G. (2005) Flavonoid-Membrane Interactions: A Protective Role of Flavonoids. Journal of Immunology Research, 12, Article ID: 592035. https://doi.org/10.1080/10446670410001722168

[10] Lee, J., Jung, E., Kim, Y., Lee, J., Park, J., Hong, S., Hyun, C.G., Park, D. and Kim, Y.S. (2006) Rosmarinic Acid as a Downstream Inhibitor of IKK-Beta in TNF-AlphaInduced Upregulation of CCL11 and CCR3. British Journal of Pharmacology, 148, 366-375. https://doi.org/10.1038/sj.bjp.0706728

[11] Khaki, A., Imani, S. and Golzar, F. (2012) Effects of Rosmarinic Acid on Male Sex Hormones (Testosterone-FSH-LH) and Testis Tissue Apoptosis after Exposure to Electromagnetic Field (EMF) in Rats. African Journal of Pharmacy and Pharmacology, 6, 248-252. https://doi.org/10.5897/AJPP11.701

[12] Al-Alami, Z.M., Shraideh, Z.A. and Taha, M.O. (2017) Rosmarinic Acid Reverses the Effects of Metronidazole-Induced Infertility in Male Albino Rats. Reproduction, Fertility and Development, 29, 1910-1920. https://doi.org/10.1071/RD16174

[13] Sabik, L.M.E. and Abd El-Rahman, S.S. (2009) Alpha-Tocopherol and Ginger Are Protective on Cyclophosphamide-Induced Gonadal Toxicity in Adult Male Albino Rats. Basic and Applied Pathology, 2, 21-29. https://doi.org/10.1111/j.1755-9294.2009.01034.x

[14] Gross, R. and Wulf, G. (1959) Klinische und experimentelle Erfahrungen mit zyk lischen und nichtzyklischen Phosphamidestern des N-Losl in der Chemotherapie von Tumoren. Strahlentherapie, 41, 361-367. [German]

[15] Anderson, D., Bishop, J.B., Garner, R.C., Ostrosky-Wegman, P. and Selby, P.B. (1995) Cyclophosphamide: Review of Its Mutagenicity for an Assessment of Potential Germ Cell Risks. Mutation Research/Fundamental and Molecular Mechanisms of Mutagenesis, 330, 115-181. https://doi.org/10.1016/0027-5107(95)00039-L

[16] Howell, S. and Shalet, S. (1998) Gonadal Damage from Chemotherapy and Radiotherapy. Endocrinology and Metabolism Clinics of North America, 27, 927-943. https://doi.org/10.1016/S0889-8529(05)70048-7

[17] Cai, L., Hales, B.F. and Robaire, B. (1997) Induction of Apoptosis in the Germ Cells of Adult Male Rats after Exposure to Cyclophosphamide. Biology of Reproduction, 56, 1490-1497. https://doi.org/10.1095/biolreprod56.6.1490

[18] Das, U.B., Mallick, M., Debnath, J.M. and Ghosh, D. (2002) Protective Effect of Ascorbic Acid on Cyclophosphamide-Induced Testicular Gametogenic and Androgenic disorders in Male Rats. Asian Journal of Andrology, 4, 201-207.

[19] Kim, S.H., Lee, I.C., Ko, J.W., Shin, I.S., Moon, C., Kim, S.-H., et al. (2016) Mechanism of Protection by Diallyl Disulfide against Cyclophosphamide-Induced Sperma- 
totoxicity and Oxidative Stress in Rats. Molecular \& Cellular Toxicology, 12, 301-312. https://doi.org/10.1007/s13273-016-0035-9

[20] Mahmoud, A.M., Soilman, H.A. and El-Hameed, A. (2016) Wheat Germ Oil Attenuates Cyclophosphamide Induced Testicilar Injury in Rats. World Journal of Pharmacy and Pharmaceutical Sciences, 5, 40-52.

[21] Ajith, T.A., Nivitha, V. and Usha, S. (2007) Zingiber officinale Roscoe alone and in Combination with Alpha-Tocopherol Protect the Kidney against Cisplatin-Induced Acute Renal Failure. Food and Chemical Toxicology, 45, 921-927. https://doi.org/10.1016/j.fct.2006.11.014

[22] Fukushima, T., Yamamoto, T., Kikkawa, R., Hamada, Y., Komiyama, M., Mori, C., et al. (2005) Effects of Male Reproductive Toxicants on Gene Expression in Rat Testes. The Journal of Toxicological Sciences, 30, 195-206.

https://doi.org/10.2131/jts.30.195

[23] Aitken, R.J. (1995) Free Radicals, Lipid Peroxidation and Sperm Function. Reproduction, Fertility and Development, 7, 659-668. https://doi.org/10.1071/RD9950659

[24] Englberger, W., Hadding, U., Etschenberg, E., Graf, E., Leyck, S., Winkelmann, J., et al. (1988) Rosmarinic Acid: A New Inhibitor of Complement C3-Convertase with Anti-Inflammatory Activity. International Journal of Immunopharmacology, 10, 729-737. https://doi.org/10.1016/0192-0561(88)90026-4

[25] Ghosh, D., Das, U.B. and Misro, M. (2002) Protective Role of Alpha-TocopherolSuccinate (Provitamin-E) in Cyclophosphamide Induced Testicular Gametogenic and Steroidogenic Disorders: A Correlative Approach to Oxidative Stress. Free Radical Research, 36, 1209-1218. https://doi.org/10.1080/1071576021000016472 